\title{
Assessing Knowledge and Application of the Design Process
}

\section{Dr. Ann Saterbak, Rice University \\ Dr. Tracy Volz, Rice University}

Tracy Volz, $\mathrm{PhD}$, is the Director of Rice University's Program in Writing and Communication. Prior to this role, she spent fourteen years teaching technical communication in the Rice Center for Engineering Leadership and in the Cain Project in Engineering and Professional Communication at Rice. In addition to working with Rice faculty and students, Dr. Volz has conducted communication seminars for professional engineering societies and corporations. Her scholarly interests focus on oral presentations, technical poster design, and pedagogical innovation. She earned a BA in English from the University of Iowa and a $\mathrm{PhD}$ in English from Rice University. 


\section{Assessing Knowledge and Application of the Design Process in a First-Year Engineering Design Course}

\section{$\underline{\text { Abstract }}$}

Authentic, client-based projects form the foundation of a one-semester freshman design course at Rice University. The course is an elective course available for all freshman students in the School of Engineering. First-year students learn the engineering design process and use it to solve meaningful problems drawn from local hospitals, industry, local community partners, Rice University, and international partners.

The objectives for the course are to (a) have students learn and practice the engineering design process early in their engineering education, and (b) increase undergraduate retention in engineering at Rice University by 10 percentage points. These two objectives align with important themes and goals published elsewhere. For this first-year design course, three specific learning outcomes have been defined: students design a product that meets user-defined needs and realistic constraints; students communicate effectively through written reports and oral/visual presentations; and students work effectively on multidisciplinary teams.

Steps in the design process form the core of the course lecture material. Most class periods are split between an interactive lecture about a step in the design process and team meetings to complete the design process, including prototype construction.

Assessment of students' knowledge of the design process was measured by asking students to critique the strengths and weaknesses of a Gantt chart. The Gantt chart laid out a 14-week design process in which a team was to develop and build an examination bed for a clinic built by Engineers Without Borders in Nicaragua. Using this recently refined assessment tool, students' knowledge and application of the design process was evaluated at the beginning and end of the semester. Written responses were coded by three trained raters on eight aspects: 1) needs assessment/establishing design criteria; 2) design context review; 3) idea generation; 4) analysis and decision-making; 5) building and testing; 6) overall layout of a design process and iteration; 7) time allotments; and 8) documentation.

Data presented in the paper includes 72 student responses from fall 2012 and spring 2013. Analysis shows statistical significance between pre- and post-test results for seven of the eight topics evaluated. The refined assessment method described here is an improvement over a previously deployed assessment tool.

\section{$\underline{\text { Introduction }}$}

Design is a critically important skill in engineering practice. As a result, it is strongly emphasized in ABET in Criteria 3 and 5 and in most senior-level capstone courses. ${ }^{1}$ Publications by experts in engineering education have clearly articulated that students need to be engaged in practice-based engineering, particularly design, from the beginning of their education. $^{2-4}$ Learning science reveals that students learn best when presented with a mixture of theoretical principles and practically-situated, open-ended problems. ${ }^{5,6}$ Thus, rather than making 
students wait for capstone design to do "real engineering," design and other open-ended problem solving opportunities should be integrated throughout the entire curriculum.

More than half of the top 25 US engineering schools run a team-based freshman design course providing students with real-world engineering opportunities. ${ }^{4,7}$ These first-year experiences provide the greatest opportunity for students to acquire baseline proficiencies in the attributes listed in the NAE "Educating the Engineer of 2020" report that can then be honed in their subsequent courses. First-year engineering experiences often focus on the key aspects of the engineering design process: research, ideation, and prototyping. Because of the central nature of design in engineering practice, students across all engineering fields can participate in multidisciplinary teams to solve authentic challenges.

Much of the assessment work for first-year engineering design courses has focused on student retention, especially women and members of underrepresented groups. ${ }^{4,-10}$ One long-term study from the University of Colorado at Boulder indicates that students who participate in a freshman year experience show retention rates $19 \%$ higher than a control group (measured at seventh semester). ${ }^{11}$ Many retention studies are summarized in Dym et al. ${ }^{3}$ While retention is also important at Rice University, we were also interested in developing an appropriate instrument to assess first-year students' knowledge and application of the design process.

Several methods are currently used to assess first-year students' knowledge of design and their application of the design process. These methods include surveys, interviews, talk aloud protocols, concept maps, exams and written reports, as well as the evaluation of students' final design prototypes. ${ }^{12-17}$ Each of these methods also has well documented limitations. Combining several methods to cross-validate results compensates for these limitations; however, triangulating and analyzing multiple sources of data require considerable time and resources.

Most methods use open-ended questioning strategies about how to attack a new design problem. For example, in the study by Kilgore et al., first-year students were asked to perform engineering tasks during timed sessions. ${ }^{17}$ One prompt was "Over the summer the Midwest experienced massive flooding of the Mississippi River. What factors would you take into account in designing a retaining wall system for the Mississippi?" Students recorded their answers on paper. The student responses were then coded and evaluated along different dimensions to evaluate how students considered the context of the challenge.

In a second example, participants in a study by Atman et al. were given a prompt to design a playground in the neighborhood of a mid-size city. ${ }^{14}$ The participants used a talk-aloud protocol to discuss how they would design such a playground. Again, responses were transcribed and coded to evaluate levels of competence across different design domain areas.

A third example is work by Bailey et al. ${ }^{18,19}$ In this study, students were asked to critique the strengths and weaknesses of a Gantt chart laying out a 14-week design process for a newly posed design challenge. Bailey and Szabo's Gantt chart tool has shown to be a quick, valid, and feasible option to assess individual design process knowledge. ${ }^{12,18,19}$ While studying students' evaluations of a Gantt chart may not provide a complete representation of students' design process knowledge; this approach has been shown to identify gaps in students' understanding, 
which is important for first-year engineering students. ${ }^{12}$ As discussed below, we have modified Bailey's method to include a specific design challenge prompt.

\section{First-Year Engineering Design at Rice University}

Introduction to Engineering Design (ENGI 120) is a one-semester client-based design course for freshman students at Rice University. The course is an elective course available for all freshman students in the School of Engineering. The objectives for ENGI 120 are to (a) have students learn and practice the engineering design process early in their engineering education, and (b) increase undergraduate retention in engineering at Rice University by ten percentage points. These two objectives align with important themes published elsewhere. ${ }^{2,4,20}$ Three specific $^{2}$ learning outcomes were established to achieve course objectives:

(1) Students design a product that meets a user-defined need and realistic constraints. Specifically, students develop realistic design criteria, apply appropriate methods for brainstorming to generate multiple design solutions, use decision matrices to select among design solution options, and iteratively prototype a physical product.

(2) Students effectively communicate progress of their design using written and oral/visual communication.

(3) Students function effectively on a high-performance team.

The content and organization of the course has been described in detail elsewhere. ${ }^{21,22}$ After the first week of class, students are placed on design teams to solve an authentic problem proposed by clients from medicine, industry, humanitarian organizations, and Rice University. Each team works on a different client-sponsored project, with four to six students per team (Table 1).

Steps in the design process form the core of the lecture material. During each class period, students work in their design teams The first half of the semester is devoted to defining the design problem, developing the design context review, establishing design criteria, brainstorming solutions, using an evaluation matrix to select a solution, and then describing the selected solution. In the second half of the semester, there are a few lectures on prototyping and testing, but most class time is set aside for teams to work on their projects. The textbook for ENGI 120 is Engineering Design: A Project Based Introduction. ${ }^{23}$

Student teams develop their solutions in the Oshman Engineering Design Kitchen (OEDK), a space where undergraduate students from all engineering departments work collaboratively on real-world, multidisciplinary design challenges. The OEDK houses a large central work area that holds individual work benches, a flexible classroom, a computer lab, a wet lab, and a machine shop. Student teams have access to a 3D ABS plastic printer, a laser cutter, a plasma cutter, a soldering station, and a printed-circuit board mill. The OEDK is also well stocked with machining equipment and tools that can be used by teams to build their projects. 
Table 1. Sample projects in ENGI 120 (2012-2013 academic year)

\begin{tabular}{|l|l|}
\hline Project Topic & Client/Sponsor \\
\hline $\begin{array}{l}\text { Medically-motivated } \\
\text { Adjustable angle rock wall } \\
\text { Training mannequin for tonsils and } \\
\text { peritonsillar abscess }\end{array}$ & $\begin{array}{l}\text { Pediatric Therapy Center } \\
\text { Physicians at Texas Children's Hospital } \\
\begin{array}{l}\text { Freezing biopsied tissue samples } \\
\text { Sampling device for dermatology }\end{array}\end{array}$ \\
\hline $\begin{array}{l}\text { Global reach } \\
\text { Stand for phototherapy lights }\end{array}$ & $\begin{array}{l}\text { Physicians at Kelsey Seybold Hospital } \\
\text { Rublic lighting for bridge in Nicaragua }\end{array}$ \\
Modification of pulse oximeter probes & Global Health Technologies (Rice Univ.) \\
\hline $\begin{array}{l}\text { Local reach } \\
\text { Playground feature }\end{array}$ & Engineers Without Borders (Rice chapter) \\
Cheetah run with lure & Global Health Technologies (Rice Univ.) \\
Kitchen themed soap dispensers & Houston Arboretum \\
Chimp water spray & Houston Zoo \\
Groundwater-derived sample evaporator & Pass and Provisions restaurant \\
\hline
\end{tabular}

Documentation is an important, on-going part of the design process. Teams submit a series of technical memos to communicate their design progress. Each technical memo focuses on a key aspect of the design process. ${ }^{22}$ During the semester, each design team gives two 15-minute oral presentations, each of which is delivered by one team member. Finally, the teams undergo two prototype checks and one final graded prototype evaluation.

\section{Development of Tool to Assess Students' Understanding of the Design Process}

To assess ENGI 120 students' knowledge of the design process, a pre- and post-test was administered at the beginning and the end of the course. Students were asked to critique a Gantt chart that laid out a 14-week schedule for an engineering design project (Figure 1). The project was to develop and build an examination bed for a clinic in Nicaragua by the student chapter of Engineers Without Borders. A brief explanation of how Gantt charts are used for project management and how to read one was provided in the test prompt to aid students with no prior exposure to Gantt charts. One page of supplemental material about Gantt charts was also made available.

Students were specifically tasked with reviewing the sample Gantt chart and elaborating on the steps in the design process, the specific strategies appropriate to accomplish the steps in the design process, and identifying the strengths and weaknesses of the proposed design process. Figure 1 also includes the specific prompt. Responses to the prompt were captured in an online course management system and varied in length from 0.5-2 pages.

The prompt used in this study was revised in summer of 2012 based on a personal communication with Bailey. Our previous efforts to measure students' design knowledge using a similar prompt in the fall of 2011 and spring of 2012 suggested that students needed more explicit instruction regarding the task, and they needed to be given a specific case to which they 
could apply their design process knowledge. ${ }^{22}$ Contextualizing the prompt is consistent with much of the literature on assessing design process knowledge. ${ }^{13,14,16,17}$

Figure 1. Pre- and post-test assessment prompt used in fall 2012 and thereafter.

Project Prompt: The Engineers Without Borders (EWB) team from Rice University has recently completed a small health clinic to serve a rural town in Nicaragua. At this time, the clinic does not contain examination tables, which are necessary as many proper physical examinations and some treatments require that a person lie down. Thus, the goal of this project is to develop and build an examination bed for the EWB-built clinic in Nicaragua.

Assignment: Critique the proposed 14-week design process to create an examination bed for the clinic in Nicaragua. This process is displayed in the Gantt chart of Figure 1.

- Elaborate on the steps in the design process with specific details.

- Elaborate on specific strategies appropriate to accomplish the steps in the design process.

- Identify the pros (advantages, strengths, etc) and cons (disadvantages, weaknesses, etc) of the proposed design process.

Note that no work on this project was done prior to what is shown in the chart.

Figure 1

\begin{tabular}{|c|c|c|c|c|c|c|c|c|c|c|c|c|c|c|}
\hline & \multicolumn{14}{|c|}{ Week } \\
\hline Activity: & 1 & 2 & 3 & 4 & 5 & 6 & 7 & 8 & 9 & 10 & 11 & 12 & 13 & 14 \\
\hline $\begin{array}{l}\text { Create many dif } \\
\text { concepts throug } \\
\text { brainstorming }\end{array}$ & & & & & & & & & & & & & & \\
\hline $\begin{array}{l}\text { Based on needs } \\
\text { most promising }\end{array}$ & & & & & & & & & & & & & & \\
\hline Build prototype & & & & & & & & & & & & & & \\
\hline $\begin{array}{l}\text { Test the prototy } \\
\text { needs are met }\end{array}$ & & & & & & & & & & & & & & \\
\hline $\begin{array}{l}\text { Make revisions } \\
\text { based on test re }\end{array}$ & & & & & & & & & & & & & & \\
\hline Build final desig & & & & & & & & & & & & & & \\
\hline Documentation & & & & & & & & & & & & & & \\
\hline
\end{tabular}

Starting in fall 2012 and continuing to the present, the modified pre-test prompt was administered during the first week of class as a take-home assignment before introducing students to the overall design process. The post-test was administered as a take-home assignment during the final exam period. At this point, all students had used their design process knowledge to complete a client-based project. Students received a maximum of two or three extra credit points on their final grade for completing both the pre- and post-test. 
In preparation for data analysis, all identifying information was stripped from the pre- and posttest responses, and they were randomized. Three trained raters evaluated the responses using a scoring rubric that was adapted from Bailey and Szabo's studies. ${ }^{18,}{ }^{19}$ Each of the eight topics (called levels) shown in Table 2 was scored on a three-point scale $(0,1,2)$.

Table 2. Design process topics evaluated in pre- and post-tests

\begin{tabular}{|l|l|}
\hline Level & Topic \\
\hline 1 & Needs assessment/Establishing design criteria \\
\hline 2 & Design context review \\
\hline 3 & Idea generation \\
\hline 4 & Analysis and decision-making \\
\hline 5 & Building and testing \\
\hline 6 & Overall layout of a design process and iteration \\
\hline 7 & Time allotments \\
\hline 8 & Documentation \\
\hline
\end{tabular}

A score of 0 indicated no mention of a topic at all or the mere naming of a topic with no further explanation. A score of 0 was also assigned for Levels 1-6 and 8, if a student's discussion of the topic focused exclusively on the amount of time designated for it in the Gantt chart (e.g., "It shouldn't take six weeks to select a concept."). A score of 1 was given if the topic was defined. A high score of 2 was awarded if a student went beyond defining the stage in the design process and elaborated on the strategies or techniques used to complete it and/or why the stage is important. The sample statements below illustrate scores of 0-2 for Level 3 (idea generation).

Score of 0: "Brainstorming should be preceded by information gathering, e.g. interviews with medical professionals in underdeveloped settings and examination of options already available."

Score of 1: "Brainstorming--It is necessary to come up with concepts based on the needs of the people."

Score of 2: "When it comes to brainstorming, there are many techniques to foster ideas. One involves index cards where each person writes an idea and passes it along to the person next to them so they may contribute to that idea and this is called the Hitchhiking method. Another method is better for large teams and involves a select panel voicing their ideas aloud and conversing with one another while the rest of the team watches while taking notes and writing down ideas of their own. During brainstorming, it is crucial that there is no judgment or criticism. This ensures that teammates are not afraid to share their ideas because they're afraid they will be rejected and humiliated."

\section{Analysis of Results Using Current Assessment Tool}

An individual student's data was included in the analysis only if both pre- and post- tests were completed. In fall 2012 the sample size was 38 (of 47 students); in spring 2013 the sample size was 34 (of 39) students. Thus, the sample size is 72, and the overall response rate was $84 \%$. Table 3 summarizes the mean and standard deviation of each level for the aggregated fall 2012 and spring 2013 data. 
Because the data are ordered categorical and paired, a generalized McNemar's test (or, StuartMaxwell test) was used to evaluate whether there are statistically significant differences between pre- and post-tests. ${ }^{24}$ For each rater at each level, the data is summarized in a $3 \times 3$ table, and a $\mathrm{P}$ value is calculated. As an example, the data and results for rater \#1 are given in the Appendix. Note that this analysis directly incorporates the pairing of the pre- and post-test data. Thus trends for pre- and post-test responses can be seen, as well as changes in student responses for each level. The test statistic and $\mathrm{P}$ value for each rater at each level were computed. The highest $\mathrm{P}$ value (i.e., most conservative $\mathrm{P}$ value) across the three raters is reported in Table 3 . While using the generalized McNemar's test is very powerful in terms of its ability to analyze paired categorical data, we are researching other statistical tools that will allow us to more robustly consider the three raters simultaneously.

Table 3. Assessment of design knowledge and application (Fall 2012, Spring 2013)

\begin{tabular}{|l|l|l|l|l|}
\hline Level & Topic & Pre-test $^{\wedge}$ & Post-test $^{\wedge}$ & P value \\
\hline 1 & $\begin{array}{l}\text { Needs assessment/Establishing design } \\
\text { criteria }\end{array}$ & $0.63 \pm 0.69$ & $1.20 \pm 0.80$ & $<0.0001$ \\
\hline 2 & Design context review & $0.55 \pm 0.77$ & $1.10 \pm 0.92$ & $<0.0005$ \\
\hline 3 & Idea generation & $1.30 \pm 0.60$ & $1.70 \pm 0.48$ & $<0.005$ \\
\hline 4 & Analysis and decision-making & $0.66 \pm 0.62$ & $1.84 \pm 0.50$ & $<0.0001$ \\
\hline 5 & Building and testing & $1.53 \pm 0.51$ & $1.85 \pm 0.36$ & $<0.05$ \\
\hline 6 & $\begin{array}{l}\text { Overall layout of a design process and } \\
\text { iteration }\end{array}$ & $1.51 \pm 0.52$ & $1.94 \pm 0.19$ & $<0.005$ \\
\hline 7 & Time allotments & $1.68 \pm 0.39$ & $1.89 \pm 0.29$ & $>0.05$ \\
\hline 8 & Documentation & $0.72 \pm 0.90$ & $1.38 \pm 0.92$ & $<0.0001$ \\
\hline
\end{tabular}

Students' knowledge and application of the design process have improved in all areas through their ENGI 120 experience (Table 3). Statistically significant increases in student knowledge of engineering design were seen for seven of the eight levels. A statistically significant increase was not observed for Time allotments (Level 7), and this may be due in part to the high pre-test score. In addition, the absolute magnitude of the post-test values are all above 1.0, and five levels are above 1.7. By using this Gantt chart assessment tool, the instructors are confident that students made substantial gains in design content and process knowledge during ENGI 120.

A test for inter-rater reliability was conducted to measure the level of agreement across the three raters' scores for each level using an unweighted method (Table 4). ${ }^{25}$ These values may be a slight overestimation since the ordered nature of the data was not accounted for directly. Overall, inter-rater reliability improved considerably as compared with a previous study by the authors using the same scoring method. ${ }^{22}$ The team still has the opportunity to improve inter-rater reliability, especially on Idea generation (Level 3), Building and testing (Level 5), Overall layout of a design process and iteration (Level 6), and Time allotment (Level 7). 
Table 4. Inter-rater reliability based on Fleiss' Kappa values

\begin{tabular}{|l|l|l|l|}
\hline Level & Topic & K (Fleiss) & Level of Agreement \\
\hline 1 & $\begin{array}{l}\text { Needs assessment/Establishing } \\
\text { design criteria }\end{array}$ & $>0.65$ & Substantial agreement \\
\hline 2 & Design context review & $>0.80$ & Almost perfect agreement \\
\hline 3 & Idea generation & $>0.55$ & Moderate agreement \\
\hline 4 & Analysis and decision-making & $>0.85$ & Almost perfect agreement \\
\hline 5 & Building and testing & $>0.50$ & Moderate agreement \\
\hline 6 & $\begin{array}{l}\text { Overall layout of a design process } \\
\text { and iteration }\end{array}$ & $>0.40$ & Moderate agreement \\
\hline 7 & Time allotments & $>0.30$ & Fair agreement \\
\hline 8 & Documentation & $>0.90$ & Almost perfect agreement \\
\hline
\end{tabular}

Comparison of Current Assessment Tool to Previous Work

Prior to fall 2012, the assessment tool differed slightly from the current assignment in that no specific design challenge was given. To assess ENGI 120 students' knowledge of the design process, a pre- and post-test was administered in which students were asked to critique a Gantt chart that laid out a 14-week schedule for an engineering design project. As shown in Figure 2, the student is asked to critique a 'generic' design process. Supplemental material about Gantt charts was made available, as described above. Administration and scoring of the assessment tool were identical to that above.

Figure 2. Pre- and post-test assessment prompt used prior to fall 2012.

Assignment: Critique the proposed design process, as displayed in the Gantt chart of Figure 1. Identify the pros (advantages, strengths, etc) and cons (disadvantages, weaknesses, etc) of the proposed design process lasting 14 weeks.

Figure 1

\begin{tabular}{|c|c|c|c|c|c|c|c|c|c|c|c|c|c|c|}
\hline & \multicolumn{14}{|c|}{ Week } \\
\hline Activity: & 1 & 2 & 3 & 4 & 5 & 6 & 7 & 8 & 9 & 10 & 11 & 12 & 13 & 14 \\
\hline $\begin{array}{l}\text { Create many diff } \\
\text { concepts throug } \\
\text { brainstorming }\end{array}$ & & & & & & & & & & & & & & \\
\hline $\begin{array}{l}\text { Based on needs } \\
\text { most promising }\end{array}$ & & & & & & & & & & & & & & \\
\hline Build prototype & & & & & & & & & & & & & & \\
\hline $\begin{array}{l}\text { Test the prototy } \\
\text { needs are met }\end{array}$ & & & & & & & & & & & & & & \\
\hline $\begin{array}{l}\text { Make revisions } t \\
\text { based on test re }\end{array}$ & & & & & & & & & & & & & & \\
\hline Build final desig & & & & & & & & & & & & & & \\
\hline Documentation & & & & & & & & & & & & & & \\
\hline
\end{tabular}


We compared the results from the contextualized prompt (Figure 1), with the results of the more generic prompt used in earlier years (Figure 2). The assessment data from the generic prompt are reprinted in Table $5 .^{22}$ Overall, there are some notable differences between this data and the more recent assessment results shown in Table 3. Note that the content, lectures, expectations, types of assignments, etc. did not change between these two academic years.

Table 5. Assessment of design knowledge and application (Fall 2011, Spring 2012) ${ }^{22}$

\begin{tabular}{|l|l|l|l|}
\hline Level & Topic & Pre-test $^{\wedge}$ & Post-test $^{\wedge}$ \\
\hline 1 & Needs assessment/Establishing design criteria & $0.36 \pm 0.50$ & $0.67 \pm 0.70$ \\
\hline 2 & Design context review & $0.47 \pm 0.67$ & $0.85 \pm 0.80$ \\
\hline 3 & Idea generation & $0.63 \pm 0.70$ & $0.77 \pm 0.74$ \\
\hline 4 & Analysis and decision-making & $0.38 \pm 0.42$ & $0.80 \pm 0.79$ \\
\hline 5 & Building and testing & $0.97 \pm 0.43$ & $1.05 \pm 0.50$ \\
\hline 6 & Overall layout of a design process and iteration & $0.92 \pm 0.75$ & $1.46 \pm 0.64$ \\
\hline 7 & Time allotments & $1.72 \pm 0.51$ & $1.86 \pm 0.35$ \\
\hline 8 & Documentation & $1.23 \pm 0.93$ & $1.86 \pm 0.35$ \\
\hline \multicolumn{2}{|l}{} \\
\hline
\end{tabular}

First, the pre-test values using the contextualized prompt are higher in five levels: Needs assessment/Establishing design criteria (Level 1), Idea generation (Level 3), Analysis and decision-making (Level 4), Building and testing (Level 5), and Overall layout of a design process and iteration (Level 6). Design context review (Level 2) and Time allotments (Level 7) are similar, and Documentation (Level 8) is lower in the contextualized prompt. Without a design project to situate their responses, students may tend to focus more on overall aspects of the design process, such as the Time allotments (Level 7) and Documentation (Level 8) rather than on the actual steps in the design process. Even without much experience in design, students are able to recognize that time allocated to "Based on needs, select the most promising concept" is too long at 6 weeks and that 1 week for "Documentation" for an intensive, semester-long project is too short. With a specific design challenge, student can more easily write about steps in the design process, and we postulate that this is why pre-test values for the contextualized prompt are higher than the pre-test values for the generic prompt for many of the listed levels.

Second, the post-test values using the contextualized prompt in Table 3 are higher than using the generic prompt in Table 5 in six levels: Needs assessment/Establishing design criteria (Level 1), Design context review (Level 2), Idea generation (Level 3), Analysis and decision-making (Level 4), Building and testing (Level 5), and Overall layout of a design process and iteration (Level 6). The values are similar for Time allotments (Level 7), and Documentation (Level 8) is lower in the contextualized prompt. Again, with or without a specific design project, students tend to write cogently about time allotments, which may be a consequence of using a Gantt chart to represent the design process. With a specific design project, students gave details and possible activities to support the steps in the design process. Work is ongoing to determine statistical significance between the administration of the two different prompts.

Most notable are the high scores in the post-test for the contextualized prompt. Previously, we were disappointed in the overall low scores for many levels (Table 5). ${ }^{22}$ Based on other 
measures of student work, such as an exam and design prototypes, we were not confident that student responses to the generic prompt were an accurate reflection of their learning. This motivated us to take a closer look at the prompt and revise it to the current contextualized prompt.

With this contextualized prompt, the post-test values for all eight levels are above 1.0. The posttest values for five levels are above 1.7. Thus, students demonstrated considerably more design process knowledge with a contextualized prompt. Given that the structure of the class was the same, we conclude that the nature and specifics of the assessment tool are critically important in being able to measure meaningful learning gains.

\section{Conclusions and Future Work}

In conclusion, we noted higher pre-test and post-test values in five or six levels, respectively, in comparing the refined contextualized Gantt chart assessment tool with the 'generic' Gantt chart assessment tool. With the contextualized prompt, students were able to demonstrate gains in design process knowledge, consistent with other measures used in the class. In this way, the refined assessment tool is now working to help faculty assess student performance and identify areas of weakness in teaching the process of engineering design.

Posing a specific, open-ended design challenge is a tool used by a number of researchers seeking to evaluate design process knowledge. Thus, our modified assessment tool is consistent with many published studies. ${ }^{14,17}$ This tool has the advantages of being quick for students to complete and simple for faculty to score.

In the future, we will continue to administer the contextualized prompt, as we believe this refined assessment tool is an efficient and meaningful way to measure changes in students' design knowledge and process gains. We will also continue to analyze the data using appropriate statistical methods. We will specifically investigate the criteria to assess Time allotments (Level 7), as this has high pre- and post-test values, as well as very low inter-rater reliability. With this reliable assessment method, we are moving forward to measure the impact of significant pedagogical changes to this class. ${ }^{26}$

\section{$\underline{\text { Acknowledgements }}$}

We would like to thank Jade Juzswik and Kathleen Wiest for assisting with data analysis. We appreciate the support of Qiwei Li with the statistics. We also appreciate the support of ENGI 120 provided by Dr. Maria Oden, Director of the OEDK.

\section{$\underline{\text { References }}$}

1. ABET, "Criteria for Accrediting Engineering Programs, 2012 - 2013," ABET, 2011. [Online]. Available: http://www.abet.org/engineering-criteria-2012-2013/. [Accessed 20 May 2012].

2. S. Sheppard, A. Macatangay, A. Colby and W. Sullivan, Educating engineers: Designing for the future in the 
field, San Francisco: Jossey-Bass, 2009.

3. C. Dym, A. Agogino, O. Eris, D. Frey and L. Leifer, "Engineering Design Thinking, Teaching, and Learning," Journal of Engineering Education, vol. January, pp. 103-120, 2005.

4. “Creating a Culture for Scholarly and Systematic Innovation in Engineering Education," American Society for Engineering Education, Washington, DC, 2009.

5. M. Prince, "Does active learning work? A review of the research," Journal of Engineering Education, vol. 93, no. 3, pp. 1-10, 2004.

6. M. Prince and R. Felder, "Inductive teaching and learning methods," Journal of Engineering Education, vol. 95, no. 2, pp. 123-138, 2006.

7. F. Bullen and D. Knight, "The Broad and Strategic Value of the Freshman Engineering Experience," International Journal of Engineering Education, vol. 22, no. 6, pp. 1241-1251, 2006.

8. M. Ohland, C. Brawner, M. Camacho, R. Layton, R. Long, S. Lord and M. Wasburn, "Race, Gender, and Measures of Success in Engineering Education," Journal of Engineering Education, vol. 100, no. 2, pp. 225$252,2011$.

9. N. Fortenberry, J. Sullivan, P. Jordan and D. Knight, "Engineering education research aids instruction," Science, vol. 317, no. 5842, pp. 1175-1176, 2007.

10. M. Ohland, S. L. G. Sheppard, O. Eris, D. Chachra and A. Layton, "Persistence, engagement, and migration in engineering programs," Journal of Engineering Education, vol. 98, no. 3, pp. 259-278, 2008.

11. D. Knight, L. Carlson and J. Sullivan, "Staying in engineering: impact of hands-on, team based, first-year projects course on student retention," in Proc. 2003 ASEE Conf. \& Expo, 2003.

12. R. Bailey and Z. Szabo, "Validation of Approaches to Assess Design Process Knowledge," in American Society of Engineering Education Annual Conference, Portland, Oregon, 2005.

13. R. Adams, P. Punnakanta, C. J. Atman and C. D. Lewis, "Comparing Design Team Self-Reports with Actual Performance: Cross-Validating Assessment Instruments," in American Society for Engineering Education Annual Conference, Montreal, Canada, 2002.

14. C. Atman, R. Adams, M. Cardella, J. Turns, S. Mosborg and J. Saleem, "Engineering Design Processes: A Comparison of Students and Expert Practitioners," Journal of Engineering Education, vol. 96, no. 4, pp. 359379, 2007.

15. D. Crismond and R. Adams, "The Informed Design Teaching and Learning Matrix," Journal of Engineering Education, vol. 101, no. 4, p. 738-797, 2012.

16. C. Atman, D. Kilgore and A. McKenna, "Characterizing Design Learning: A Mixed-Methods Study of Engineering Designers' Use of Language," Journal of Engineering Education, vol. 97, no. 3, pp. 309-326, 2008.

17. D. Kilgore, C. Atman, K. Yasuhara, T. Barker and A. Morozov, "Considering Context: A Study of First-Year Engineering Students," Journal of Engineering Education, vol. 96, no. 4, p. 321-334, 2007.

18. R. Bailey and Z. Szabo, "Assessing engineering design process knowledge," International Journal of Engineering Education, vol. 22, no. 3, pp. 508-518, 2006.

19. R. Bailey, "Effects of industrial experience and coursework during sophomore and junior years on student learning of engineering design," Transactions of the ASME, vol. 129, pp. 662-667, 2007.

20. "Educating the Engineer of 2020: Adapting Engineering Education to the New Century," The National Academies Press, Washington, DC, 2005.

21. A. Saterbak, M. Embree and M. Oden, "Client-based projects in freshman design," in American Society of Engineering Education Conference Proceedings, San Antonio, 2012.

22. A. Saterbak and T. Volz, "Assessing Design Capabilities Following a Client-Based Freshman Design Course," in 4th First-Year Engineering Experience Conference, Pittsburgh, PA, 2012.

23. C. Dym and P. Little, Engineering design: A project-based introduction, Hoboken, NJ: John Wiley and Sons, 2004.

24. X. Sun and Z. Yang, "Generalized McNemar's Test for Homogeneity of the Marginal Distributions," in SAS Global Forum, Statistics and Data Analysis, San Antonio, 2008.

25. K. L. Gwet, “AgreeStat 2011.2/3 for MS Excel; Advanced Analytics; PO Box 2696; Gaithersburg, MD 208862696," Advanced Analytics, LLC, 2011. [Online]. Available: http://www.agreestat.com/agreestat.html. 
[Accessed 12 July 2012].

26. A. Saterbak, M. Wettergreen, A. Muscarello and Z. Oden, "Teaching Freshman Design Using a Flipped

Classroom Model," in American Society of Engineering Education Conference Proceedings, Indianapolis, 2014.

\section{$\underline{\text { Appendix }}$}

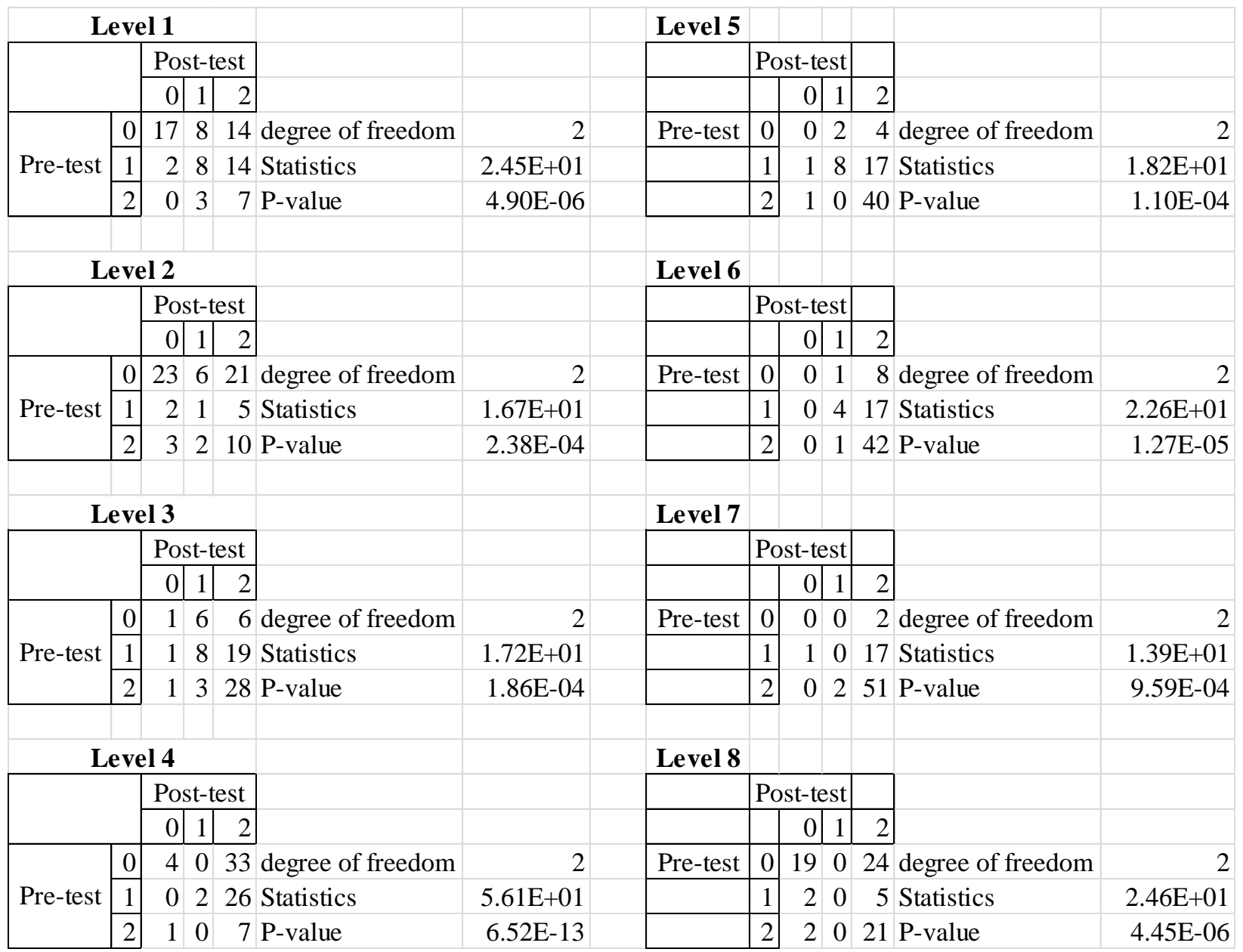

